\title{
Multiple Signal Source Terrain Topography Determination using Labview VI Algorithm
}

\author{
Ryann A. Alimuin, Argel A. Bandala, Elmer P. Dadios
}

\begin{abstract}
To apply the knowledge in hardware and software integration, as well as utilizing the NI LabVIEW and NI myDAQ signal acquisition attribute. The aim of this research paper is to provide a solution for determining the type of land topograhy through the detection of incoming multiple groundwave signals from different oscillation sources. Aside from source determination and notification, the user will also be able to visualize, analyze, and classify the type of the incoming signal which depends upon its response as it passes through an indefinite terrain. The system will be using Low Frequency $(L F)$ ground-wave oscillations. This paper deals with the concern using the finite-difference time-domain (FDTD) of topographic terrain identification through soil conductivity and creating a virtual instrument (vi) that will execute a determination algorithm. The LabVIEW program that will be implemented is multiplatform, it will be able to support different versions of LabVIEW depending on the program availability and to support real-time targets.
\end{abstract}

Index Terms: About four key words or phrases in alphabetical order, separated by commas.

\section{INTRODUCTION}

Today, the advancement of science, technology and engineering is increasing in rapid phase. Progress in computer-based hardware and integration is very much implemented including other technologies and innovations [1]. Due to these present knowledge about softwares and sensor integrations, past problems that are found to be difficult to deal with can now be easily solved. LabVIEW is graphical programming environment has several features that allow the developer to easily create engine test software [2]. Programming knowledge of any other language is not required [3]. It is a software application from National Instruments that is specially designed for easy and powerful data recording, visualization and analysis [4]. A LabVIEW application can be customized which is referred to as a Graphical User Interface (GUI) or Human Machine Interface (HMI). LabVIEW offers the ability to work at a higher layer of abstraction than typical text based programming languages like $\mathrm{C}$ [5]. This application is designed with functionalities like data acquisition via wireless communication [6].

Revised Manuscript Received on August 19, 2019. Institute of the Philippines - Quezon City, Philippines.

Argel A. Bandala, Electronics and Communications Engineering Department, De La Salle University - Manila, Philippines. Salle University - Manila, Philippines.
Ryann A. Alimuin, Electronics Engineering Department, Technological

Elmer P. Dadios, Manufacturing Engineering and Management, De La

For disasters such as fires and earthquakes, models for near-ground wave propagation are studied through-wall imaging and detection techniques, which have varieties of applications [7]. Utilization of Parabolic approximation using Helmholtz equation for Path loss prediction models are also done [8] while others use Deconvolution approach which is dependent on a number of limiting conditions and sensitive to model errors [9].

LabVIEW DAQ on the other hand This paper illustrates a proposal of a LabVIEW based virtual instrument and Data Acquisition (DAQ) model that enables detection of ground-wave signals coming from multiple sources under different geographical terrains. The received signals can be used for analyzing terrain obstructions for natural catastrophes.

\section{RELATED WORK ON GROUND WAVE AND DATA ACQUISITION}

LabVIEW provides highly convenient environment for simulation development and also tools for generation of simulation environment [10]. It is used in the experiment for developing and testing of VI modules using the front panel and real-time engine through remote data acquisition, control and analysis [1]. It VIs are used substitute for classical measuring instruments [11]. For effective intelligent time-frequency joint detection method, it implements programming for the downhole acoustic telemetry systems then analyzes the signal transmission characteristics and noise distribution law, as well as weak signal detection [12] . Topside controllers using LabVIEW are developed for the purpose of pilot training as well as the development of a control system for an Underwater Robotics Vehicle (URV) and exchange online data between different operating systems [13].

Recent ground wave studies proposes an efficient semi-analytic model for near-ground wave propagation in indoor scenarios for transceivers deployed in indoor environments on or near the ground [7]. Simulation method of Synthetic Aperture Radar (SAR) scattering signal of big area terrain target uses imaging principles where echoes of point target are calculated [14]. A bistatic VHF-band SAR experiment demonstrates signal-to-clutter enhancement in 
forested and urban terrain [15] and frequency correction is applied to justify for frequency separation between the transmitter output and the receiver response [16].

\section{COMPONENTS AND SYSTEM ARCHITECTURE REQUIREMENTS RESULTS}

The system is a Virtual Instrument that uses a LabVIEW front panel and the DAQmx assistant which functions as the channel for data acquisition. The primary objective of is the construction of a VI that notifies the user which positioned transmitter sends an irregular signal and displays onto the user the change in the waveform oscillation. The user would be able to determine the cause of the signal attenuation depending upon the reception at the signal receiving endpoint.

A. The following are the components of the system:

1. Ground-wave oscillators

2. Signal receivers/Tranducers

3. NI myDAQ

4. Personal Computer/laptop

5. NI LabVIEW

6. Dual Polarity Power supply

B. The following are the computer hardware specifications necessary to operate the structure:

1. Pentium 4M Processor or higher

2. 1 GB of RAM or higher

3. 32 or 6 bit Windows 7/8/8.1/10

4. Free $20 \mathrm{~GB}$ hard drive storage for system software requirements

\section{Screen resolution of at least $1024 \times 768$ pixels}

The hardware and software system requirements stated are based upon the minimum requirements needed to run LabVIEW 2015 and NI myDAQ, the system requirements establishes the components for building the system such as software tools, and other necessary components [17]. LabVIEW provides visual quality and has extensive signal process function library [12]. Higher specification computers can increase the speed of program, signal reception, efficiency as well as the system performance. Higher versions of LabVIEW with complete tools and plug-ins may require higher operating systems as well as superior hardware necessity.

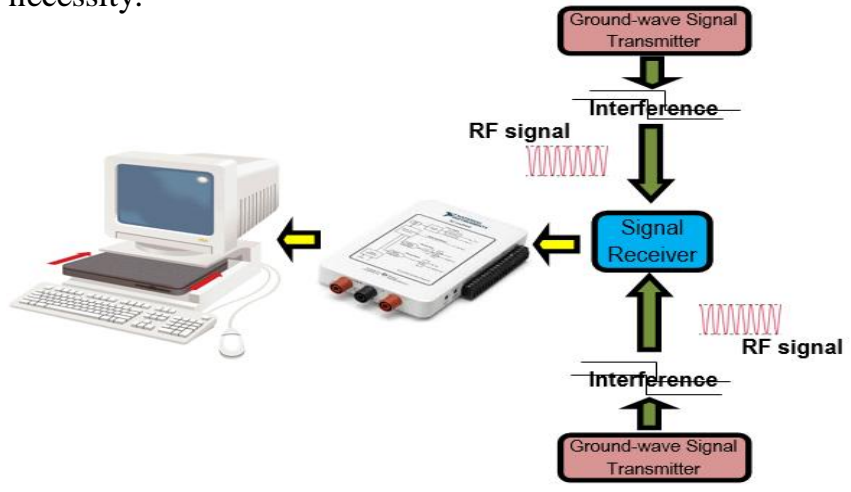

Figure 1. System Block Diagram
The hierarchy in

is comprised of multiple ground-wave oscillators deployed in specific areas positioned with respect to the terrain. The oscillator then continuously monitors the propagating waves across the terrain, as an object/entity interferes and distrupt the propagating waves, LabVIEW automatically notifies the user for a signal distruption and notifies which transmitter gave the particular signal. The user was then shown an irregular output waveform made by the interference, this is where the user can then isolate the problem.

The LabVIEW VI contains the following:

1. Boolean Indicator for Detection

2. Waveform chart for Signal Analysis

3. Signal Threshold Adjustment

4. Frequency Counter

5. Excel Spreadsheet Data Import

\section{A.LabVIEW Signal Acquisition}

LabVIEW and DAQ have been widely utilized to update and modernize equipment and laboratory experimental apparatus [18], it can be used to integrate circuits and systems. The signal acquisition made by the system is implemented through the following steps:

- A low frequency signal is applied to the terrain through oscillators with predetermined locations.

- Audio transducers connected to NI MyDAQ receives the incoming signal

- The LabVIEW program discerns the nature of the sound

- Through a Boolean Indicator, the program displays which transmitter is sending the signal.

- A graph displays the waveform of the incoming signal

- The user was shown the signal and is able to save the data and import it onto an excel file.

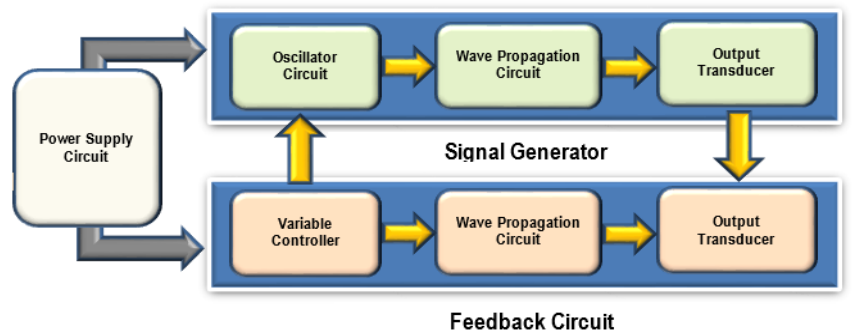

Figure 2. Block Diagram of the VLF Groundwave Propagation Circuit

Figure 2 presents the Block Diagram of the internal circuit structure. The circuit is comprised of a DC power supply that energizes the whole system. The Signal Generator provides several output waveforms as well as amplitude modulation of the output signal [19] is comprised of an oscillator circuit that produces multiple waveforms, a wave

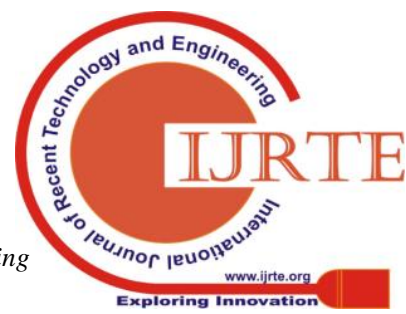


propagation circuit that implements forward masking method to propagate sound through the ground and an output transducer. The Feedback Circuit enables the parameters to be varied depending upon the state of the terrain topography, it can also reduce the power consumption by controlling the gain and maximize overall dynamic range [20]. It is constituted by a frequency counter for measuring the applied signal, a comparator circuit which is a fundamental component of current-mode signal processing [21] used for taking the difference of the applied input signals and a variable controller for regulation of the output parameters.

\section{Terrain Analysis}

Radio waves are employed to transmit information from point to point, from source to observer around the earth [22]. The two dimensional finite-difference time-domain (FDTD) algorithm is applied to calculate the field strength of the low frequency (LF) ground wave propagating over irregular terrains. The propagation characteristics are studied as functions of the mountain's gradient, height, and width, respectively [23]. FDTD-based propagation model solves Maxwell's equation directly using centered finite difference method [24]. For propagation over distances less than $100 \mathrm{mi}$, the field intensity follows the theoretical inverse distance law for ground waves over a perfect ground plane. From 100 to about $400 \mathrm{mi}$, the field intensity falls off approximately as the inverse distance cubed [25]. The terrain function of the Gaussian-shaped Mountain is given by:

$$
(\rho)=H e^{-q\left(\rho-\frac{\rho_{0}}{I}\right)^{2}} \quad \text { Equation (1) }
$$

Where $\rho$ is the distance, $l$ is a parameter for controlling the mountain width, $H$ is the height, and $\rho_{0}$ is the distance from the antenna to the center of the mountain.

The electrical field strength can be expressed as a function of the ground wave attenuation factor [26]:

$$
E_{z}=\frac{i 120 \pi I d l}{\lambda a \sqrt{\theta \sin \theta}} e^{i k a \theta} W \quad \text { Equation (2) }
$$

Path loss is the results of signal loss, which occurs due to obstruction in environment factors, the Hata-Okumura model applicable for a frequency range of 150-1500 MHz. Hata model provides extension to Okumura model for distance higher than $1 \mathrm{~km}$. It does not perform well for higher frequencies and smaller sizes [27].

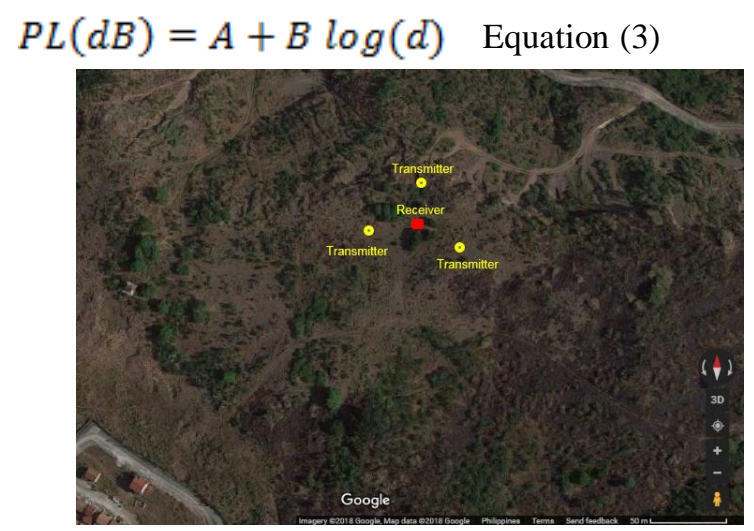

Retrieval Number: B10790882S819/2019@BEIESP

\section{Figure 3. Terrain Test site at Teresa Rizal, Philippines}

Figure 3 shows the test site in Teresa Rizal, Philippines in which multiple oscillators are planted in different areas in which inclination and soil conditions are uneven. These are done to differentiate the different responses of reception from different slopes and terrain. Irregularities in the terrain have a great effect on the ground wave field strength [28].

\section{LabVIEW Signal Source Detection}

The DAQ system can be utilized for real-time remote monitoring of important electrical parameters like root mean square (rms) voltage, rms current and peak-peak voltage [29]. Due to propagation loss, amplitudes of multiple working frequencies are used for target identification [30]. The program demonstrated on how it was able to detect and display incoming signal strength from different transmitting sources.

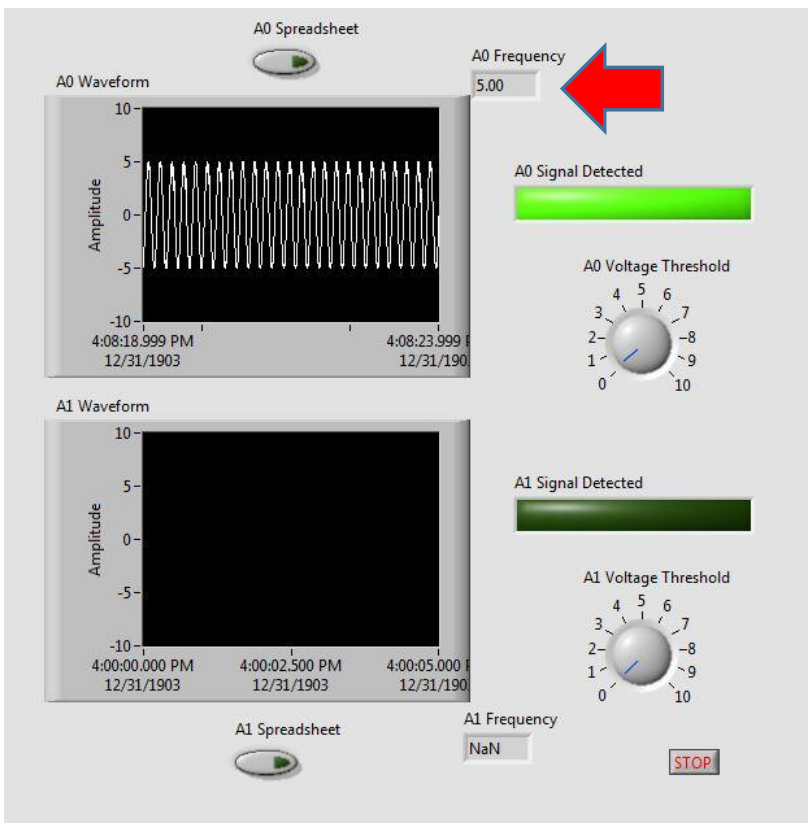

Figure 4. A0 Signal Reception

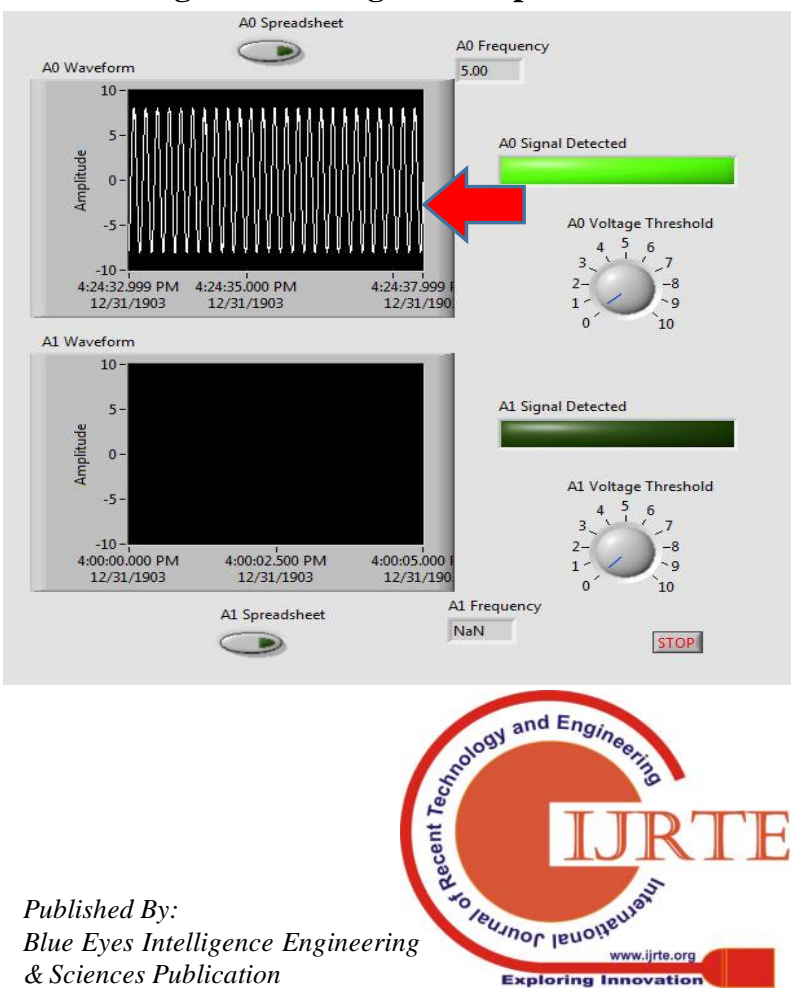


Figure 5. A0 Amplitude Increases

As shown in Figure 4, the Boolean indicator displayed that an incoming signal is detected across the first receiver. The graph displayed the amplitude of the signal as well as the signal frequency through the frequency counter. A higher amplitude was detected due to conduction of a wet terrain as seen in Error! Reference source not found.

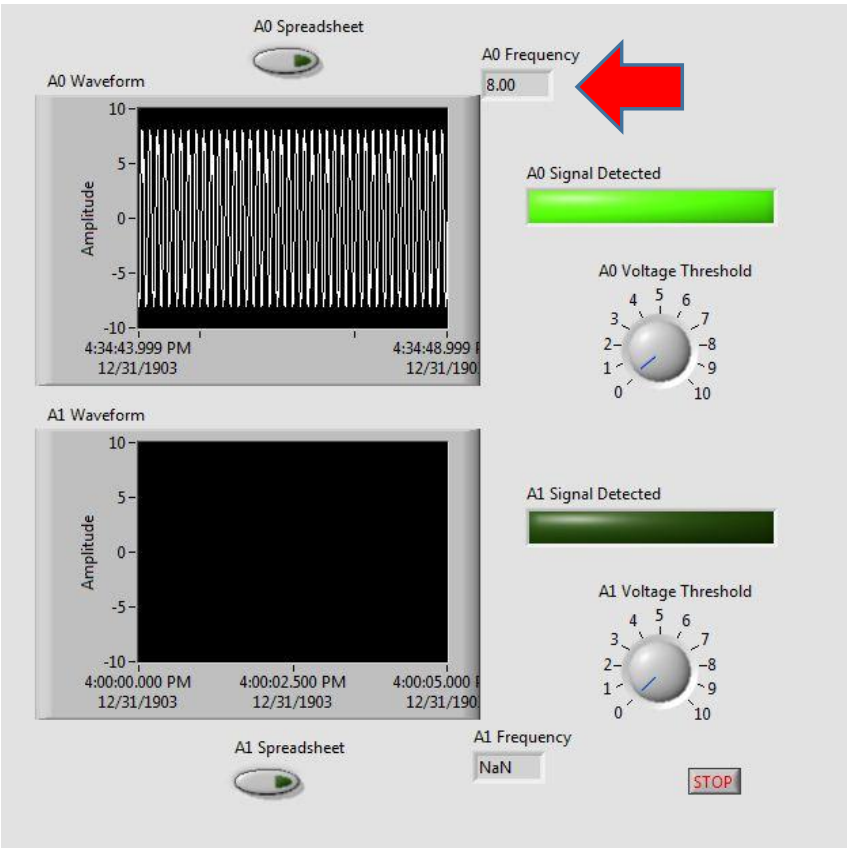

Figure 6. A0 frequency increases

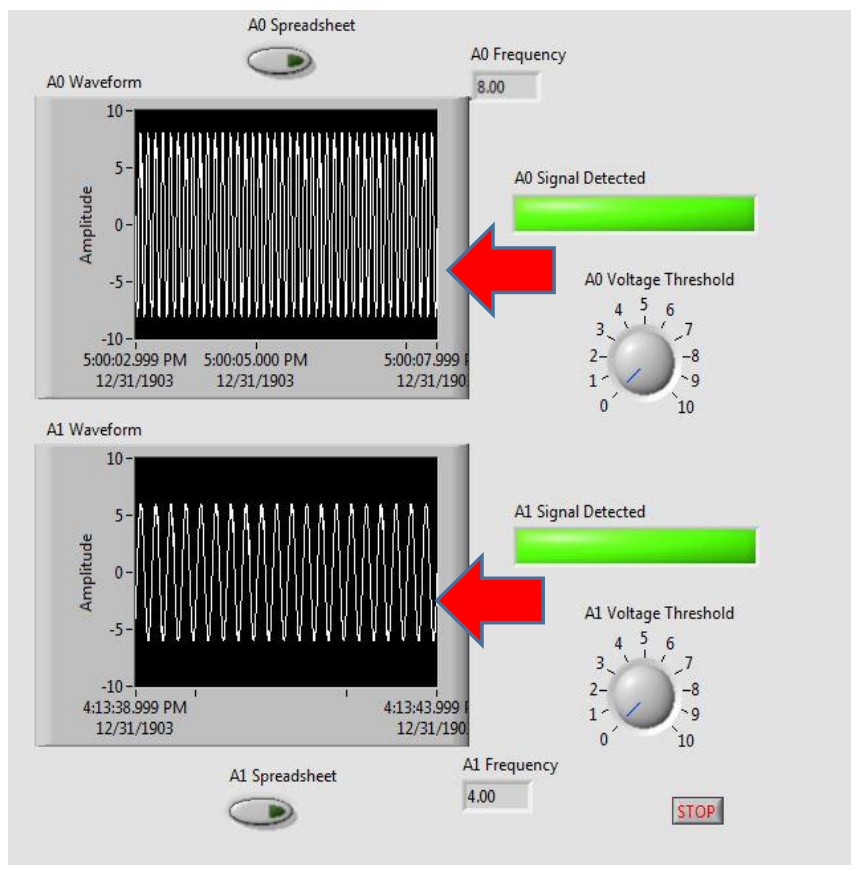

Figure 7. Simultaneous reception of incoming signals

With greater soil conduction, the program detects a very high amplitude higher frequency as shown in Figure 6. Figure 7 shows the active system that detects two signals with different amplitudes and frequency. The variation differs depending upon the terrain travelled as well as the distance for the receiving end.

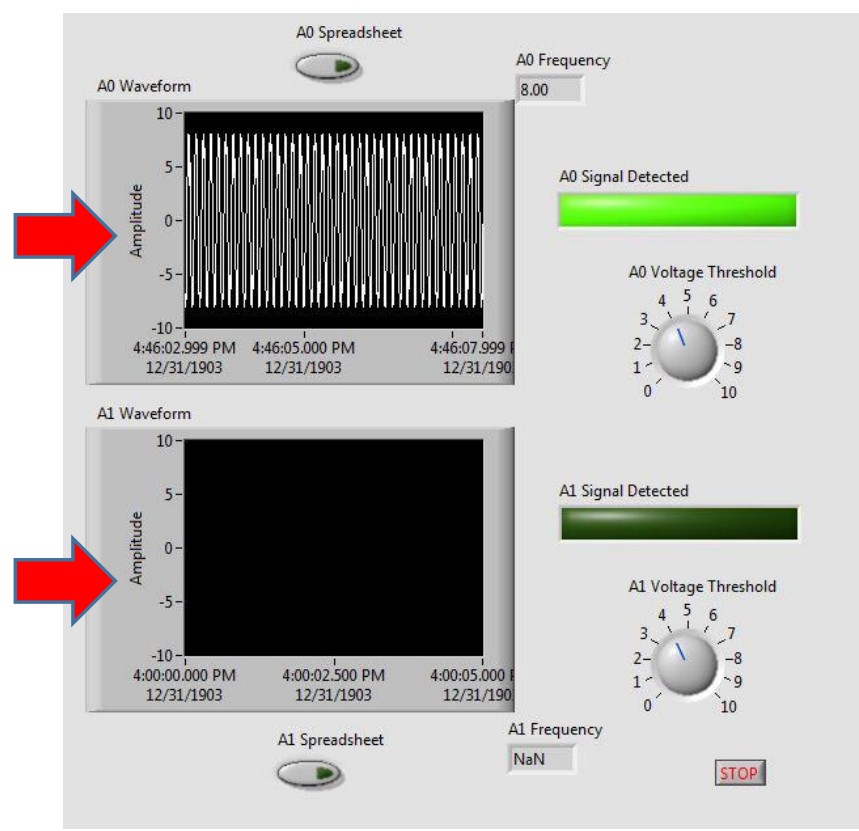

Figure 8. Threshold Adjustment for greater tolerance

In Figure 8, as the threshold is adjusted to a value with greater tolerance than the input signal, the signal will be left undetected unless the amplitude of the incoming signal will be greater than the threshold. Clicking the Spreadsheet button will allow the user to save the signal and convert the plotted data to excel format.

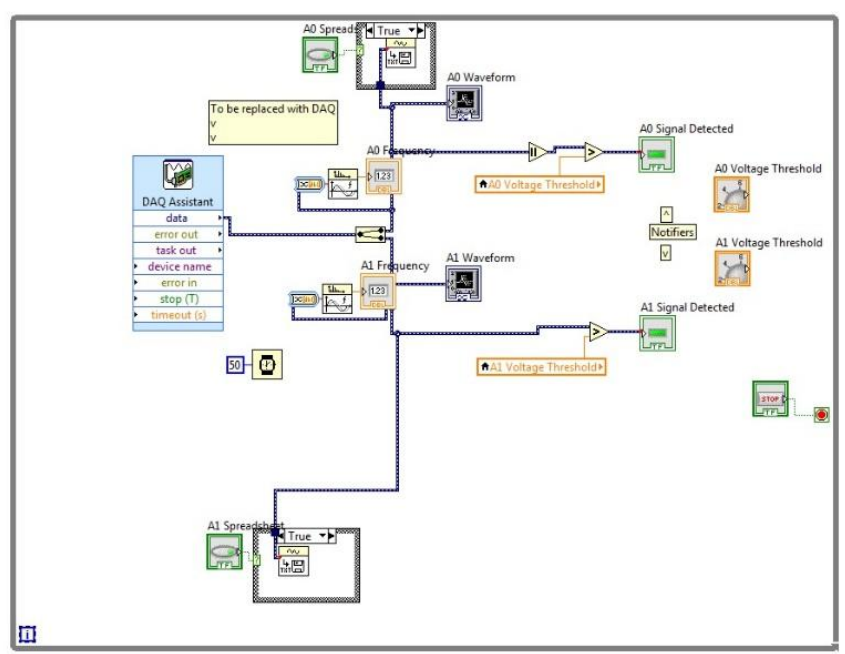

Figure 9. The VI Algorithm Diagram

The VI Algorithm Diagram in Figure 9 illustrates the main VI program of LabVIEW system. The DAQ Assistant serves as the interface between the hardware and the software, it provides the data that will be processed by the system. The speed of system execution is dependent upon the computer CPU and internal memory.

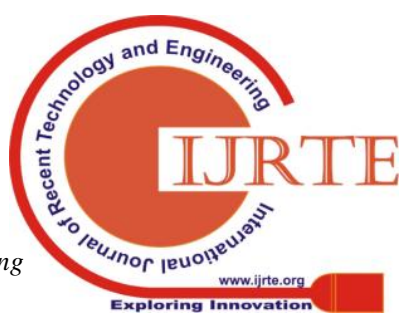


Audio signal strength $(d B)$ in terms of Distance

Table 1. Signal Strength vs. Distance

Distance (ft)

\begin{tabular}{|c|c|c|c|c|c|c|}
\hline \multirow{11}{*}{ 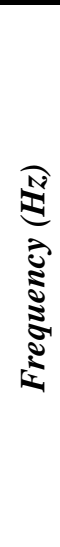 } & & 1.67 & 3.33 & 5 & 6.676 & 8.33 \\
\hline & 100 & $64 \mathrm{~dB}$ & $57 \mathrm{~dB}$ & $55 \mathrm{~dB}$ & $53 \mathrm{~dB}$ & $52 \mathrm{~dB}$ \\
\hline & 200 & $64 \mathrm{~dB}$ & $60 \mathrm{~dB}$ & $58 \mathrm{~dB}$ & $58 \mathrm{~dB}$ & $53 \mathrm{~dB}$ \\
\hline & 300 & $66 \mathrm{~dB}$ & $62 \mathrm{~dB}$ & $58 \mathrm{~dB}$ & $57 \mathrm{~dB}$ & $57 \mathrm{~dB}$ \\
\hline & 400 & $68 \mathrm{~dB}$ & $63 \mathrm{~dB}$ & $59 \mathrm{~dB}$ & $57 \mathrm{~dB}$ & $57 \mathrm{~dB}$ \\
\hline & 500 & $66 \mathrm{~dB}$ & $61 \mathrm{~dB}$ & $58 \mathrm{~dB}$ & $54 \mathrm{~dB}$ & $53 \mathrm{~dB}$ \\
\hline & 600 & $66 \mathrm{~dB}$ & $61 \mathrm{~dB}$ & $57 \mathrm{~dB}$ & $54 \mathrm{~dB}$ & $53 \mathrm{~dB}$ \\
\hline & 700 & $67 \mathrm{~dB}$ & $60 \mathrm{~dB}$ & $58 \mathrm{~dB}$ & $53 \mathrm{~dB}$ & $52 \mathrm{~dB}$ \\
\hline & 800 & $67 \mathrm{~dB}$ & $60 \mathrm{~dB}$ & $59 \mathrm{~dB}$ & $56 \mathrm{~dB}$ & $53 \mathrm{~dB}$ \\
\hline & 900 & $65 \mathrm{~dB}$ & $59 \mathrm{~dB}$ & $55 \mathrm{~dB}$ & $54 \mathrm{~dB}$ & $52 \mathrm{~dB}$ \\
\hline & 1000 & $69 \mathrm{~dB}$ & $62 \mathrm{~dB}$ & $60 \mathrm{~dB}$ & $57 \mathrm{~dB}$ & $52 \mathrm{~dB}$ \\
\hline
\end{tabular}

The masked audio signal being emitted is attenuating with respect to the distance travelled by the ground-wave as well as the topography of the terrain though soils and rocks.

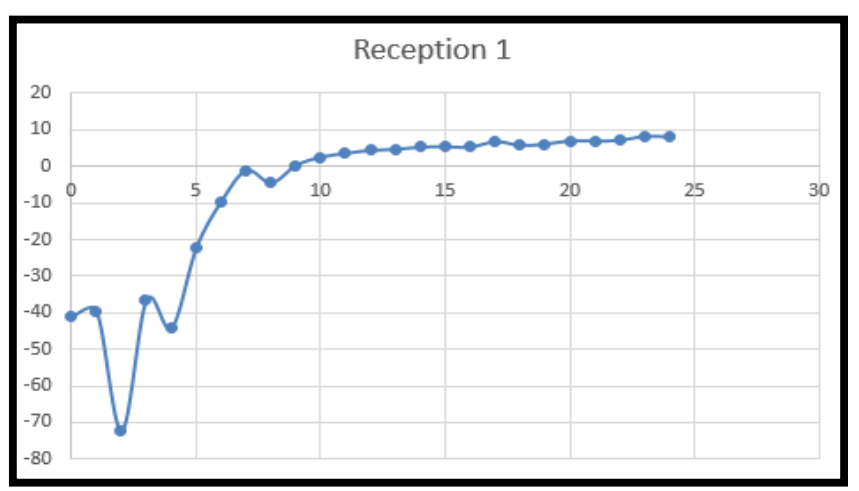

Figure 10. Initial Signal Reception

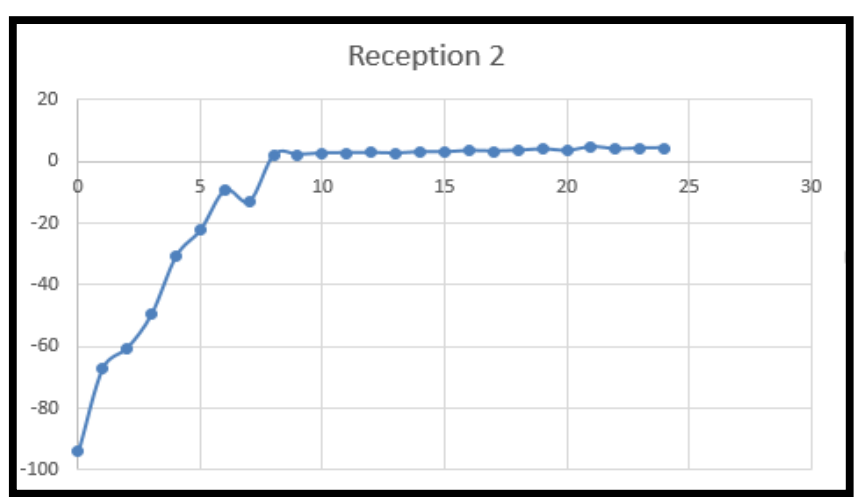

Figure 11. Second Signal Reception

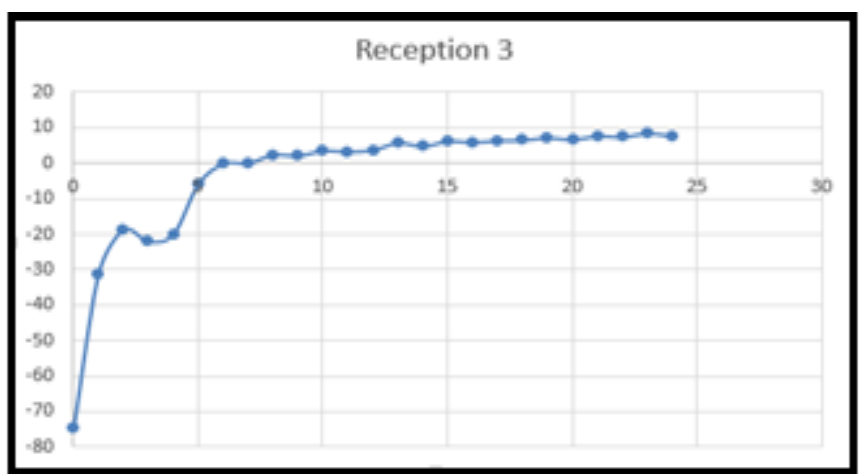

Figure 11. Third Signal Reception

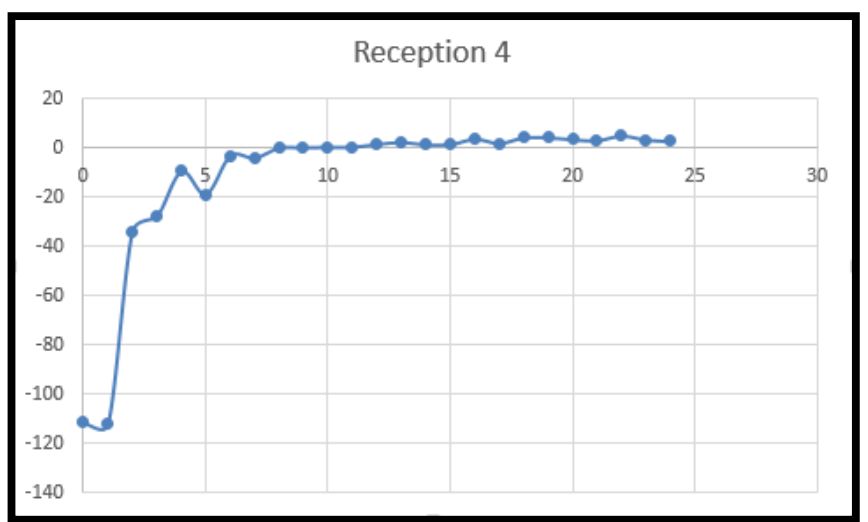

Figure 12. Fourth Signal Reception

Figure 12 illustrates the signal information with respect to time. Changes in amplitude is recorded.

Figure 10 presents the system response for a rocky terrain, as the signal reaches the flatland, the reception became unchanging.

Figure 11. Second Signal Reception

is the response for geographical terrain with lesser rocks and more soil, and 
Figure 12 illustrates loam soil conditions, water inside the soil promotes greater signal conductivity upon reaching the receiver. The 4 th response in

Figure 12 has the highest stability in terms of reception in ground wave propagation due to a higher masked frequency transmission. It was able to withstand terrain obstructions and is able to recover the signal.

\section{CONCLUSIONS AND RECOMMENDATIONS}

The signal detection system can be used to determine the conductivity and topography of the terrain through waveform analysis. It will also allow monitoring of objects at the terrain that the signal passes through. The waveforms received presents the signal loss under different environmental conditions. The system utilizes the LabVIEW platform for display, data acquisition, and file importation. The features can be used in variety of ways especially in gathering soil information as well as terrain study. The system can be modified to increase its performance in gathering a more accurate signal reception. Accurately tuned transmitter oscillator Receiver transducer sensitivity NI my DAQ with numerous inputs and expansion slots Increased computer hardware specifications

\section{ACKNOWLEDGMENT}

The research proponents express their deep gratitude to the Technological Institute of the Philippines - Quezon City and De La Salle University for the collaborative research and experimentation. We would also acknowledge their permission on the use of relevant equipment and apparatuses for the design.

\section{REFERENCES}

1. M. Fulton, M. Swain, J. A. Anderson, A. Singh, N. K. Swain, J. Garrett, and O. Tucker, "Remote data acquisition, control and analysis using labVIEW front panel and real time engine," pp. 1-6, 2004.

2. P. Turley and M. Wright, "Developing engine test software in LabVIEW," no. 210, pp. 575-579, 2002.

3. I. Titov and E. Titov, "Labicom.net - Putting your laboratory online in less than five minutes with WebPager tool: Automatic generation and HTML page," Proc. - 2013 2nd Exp. Int. Conf. exp.at 2013, pp real-time control of a LabVIEW based laboratory server from pluginless

180-183, 2013

4. M. Murugappan, R. Thirumani, M. I. Omar, and S. Murugappan, "Development of cost effective ECG data acquisition system for clinical applications using LabVIEW," Proc. - 2014 IEEE 10th Int. Colloq Signal Process. Its Appl. CSPA 2014, pp. 100-105, 2014.

5. A. Mason and S. Parkes, "Using SpaceWire with LabVIEW," Proc. 6th Int. SpaceWire Conf. SpaceWire 2014, 2014.

6. M. John and A. Joseph, "Implementation of automated demand side energy monitoring on TOD basis using LabVIEW," 2014 Int. Conf. Adv. Electr. Eng. ICAEE 2014, 2014

7. F. T. Dagefu and K. Sarabandi, "Analysis and modeling of near-ground wave propagation in the presence of building walls," IEEE Trans. Antennas Propag., vol. 59, no. 6 PART 2, pp. 2368-2378, 2011.

8. R. Janaswamy, "Path Loss Predictions in Urban Areas with Irregular Terrain Topography," pp. 255-268, 2000.

9. A. Nelander, "Deconvolution approach to terrain scattered interference mitigation," pp. 344-349, 2003.

10. E. Vavilina and G. Gaigals, "Improved LabVIEW code generation," Adv. Information, Electron. Electr. Eng. AIEEE 2015 - Proc. 2015 IEEE 3rd Work., pp. 5-8, 2015.

11. N. Popović, S. Stankovski, B. Popović, G. Ostojić, and D. Mijić, "Remote control of laboratory equipment for basic electronics courses: A LabVIEW-based implementation," Comput. Appl. Eng. Educ., vol. 21, no. S1, pp. E110-E120, 2011.

12. X. Liu and X. Feng, "Research on Weak Signal Detection for Downhole Acoustic Telemetry System," vol. 1, pp. 1-5, 2010.

13. M. W. S. Lau, G. G. L. Seet, E. Low, Xunzhang Wang, and K. C. Tan "Exploiting force feedback in pilot training and control of an underwater robotics vehicle: an implementation in LabVIEW," no. 65, pp. 2037-2042, 2002.

14. X. Pan, Y. Wu, and X. Jia, "A novel method of SAR terrain target scattering signal simulation,” Proc. - 2010 3rd Int. Congr. Image Signal Process. CISP 2010, vol. 6, no. 1, pp. 2961-2965, 2010.

15. B. Flood, P.-O. Frölind, E. Meier, J. Rasmusson, L. M. H. Ulander, A Gustavsson, G. Stenström, A. Barmettler, and T. Jonsson, "Signal-to-clutter ratio enhancement in bistatic very high frequency (VHF)-band SAR images of truck vehicles in forested and urban terrain," IET Radar, Sonar Navig., vol. 4, no. 3, p. 438, 2010.

16. M. S. Sai Krishna Bhargav, B. Venkata Ramana, K. Chandra Bhushana Rao, and P. Siva Kumar, "Prediction and analysis of electromagnetic interference in radio frequency propagation for transmitter-Receiver pair using LabVIEW,” Proc. Int. Conf. Electromagn. Interf. Compat., pp. 2-5, 2017.

17. National Instruments, "LabVIEW Development Guidelines," no. 321393. National Instruments, 2000.

18. H. I. Abu-Mulaweh and D. W. Mueller, "The use of LabVIEW and data acquisition unit to monitor and control a bench-top air-to-water heat pump," Comput. Appl. Eng. Educ., vol. 16, no. 2, pp. 83-91, 2008.

19. Delta University, "Signal Generators," Industrial Area. Mansoura, Gamasa Egypt.

20. W. T. Lee, J. Lee, and J. Jeong, "Design of variable gain low noise amplifier using feedback circuit with memory circuits for $5.2 \mathrm{GHz}$ band,' Analog Integr. Circuits Signal Process., vol. 68, no. 1, pp. 43-50, 2011.

21. Lu Chen, Bingxue Shi, and Chun Lu, "A robust high-speed and low-power CMOS current comparator circuit," pp. 174-177, 2002.

22. J. R. Johler, "Propagation of the Low-Frequency Radio Signal," pp 404-427.

23. L. Zhou, X. Xi, J. Liu, and N. Yu, "LF ground-wave propagation over irregular terrain," IEEE Trans. Antennas Propag., vol. 59, no. 4, pp. 1254-1260, 2011.

24. K. Wu, J. W. Schuster, and R. J. Luebbers, "Full wave modeling of RF propagation between low-to-the-ground antennas," IEEE Antennas Propag. Soc. AP-S Int. Symp., vol. 2 B, pp. 711-714, 2005.

25. S. W. Halpern, "A Study of Environmental Constraints in the Coastal Harbor Radiotelephone System," IEEE Trans. Veh. Technol., vol VT-25, no. 3, pp. 226-238, 1977.

26. T. S. M. Z.Wu, "Radiowave Propagation Over Ground," J. Atmos. Terr. Phys., pp. 14-15, 1995

27. P. K. Sharma and A. L. P. L. Model, "Comparative Analysis of Propagation Path loss Models with Field Measured Data," vol. 2, no. 6 , pp. 2008-2013, 2013.

28. L. L. Zhou, X. L. Xi, N. M. Yu, and Y. R. Pu, "Modelling of LF ground-wave propagation at short distances based on 2-D cylindrical-coordinate FDTD method," ISAPE 2008 - 8th Int. Symp. Antennas, Propag. EM Theory Proc., pp. 855-858, 2008.

29. N. Khera, "Development of Lab VIEW based Electrical Parameter Monitoring System," 2015.

30. G. Wu and W. Deng, "HF Radar Target identification Based on Optimized Multi-frequency Features," pp. 307-316, 2009. 


\section{AUTHORS PROFILE}

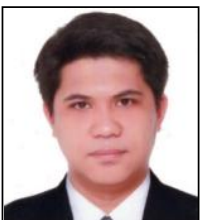

Ryann A. Alimuin is an Assistant Professor and a Faculty Member of the Electronics Engineering Department at Technological Institute of the Philippines Quezon City.

2007 - Received B.S. Degree in Electronics and Communications Engineering, Technological Institute of the Philippines - Q.C.

2012 - Received Master of Engineering Program, Technological University of the Philippines - Manila

2019 - Pursuing Ph. D in Electronics Engineering, De La Salle University Manila

Main Works:

- Design of a 4-Channel Virtual Instrument Video Adapter for Digital Data Multiplexing

- Surveillance Systems Integration for Real Time Object Identification using Weighted Bounding Single Neural Network

- Design of a Single Input Multiple Output (SIMO) Power Management System with Load Balancing and Automatic Current Regulation

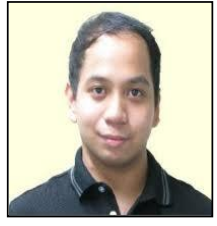

Argel A. Bandala is an Associate Professor and Faculty Member of the Electronics and Communications Engineering Department of De La Salle University Manila

2008 Received Bachelor of Science in Electronics and Communications Engineering, Polytechnic University

2012 - Graduated from Master of Science, De La Salle University

2012 - Faculty Member, De La Salle University

2015 - Received Ph.D., De La Salle University Main Works:

- Development and Design of Mobile Robot with IP-based Vision System

- Swarming Algorithm Behavior for Aggregation, Forging, Formation and

Tracking.

Membership in Academic Societies:

- The Institute of Electrical and Electronics Engineers (IEEE)

- Vice Chair, Institute of Electrical and Electronics Engineers (IEEE), Philippine Section

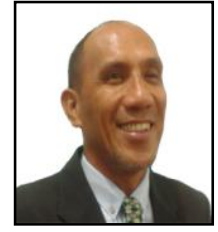

$\mathrm{La}$

EImer P. Dadios is a University Fellow and Professor at De La Salle University and President of NEURONEMECH, Inc.

1996 Received the Doctor of Philosophy, Loughborough University 1997 Exchange Scientist, Japan Society for the Promotion of Science, Tokyo Institute of Technology 1998- 1999 Director, Engineering Graduate School, De

$$
\text { Salle University }
$$

2003-2004 Director, School of Engineering, De La Salle University 2003, 2005, 2007, 2009, 2011, 2013, 2015, 2017 General Chair of the International Conference on Humanoid, Nanotechnology, Information Technology, Communication and Control, Environment, and Management (HNICEM)

Main Works:

- "Fuzzy Logic - Controls, Concepts, Theories and Applications," ISBN 978-953-51-0396-7.

- "Fuzzy Logic - Algorithms, Techniques and Implementations," ISBN 978-953-51-0393-6.

- "Fuzzy Logic - Emerging Technologies and Applications," ISBN 978-953-51-0337-0

Membership in Academic Societies:

- Senior Member, The Institute of Electrical and Electronics Engineers (IEEE)

- Founder and Chair of the IEEE Computational Intelligence Society, Philippines

- IEEE Region 10 Executive Committee

- Founder and President of the Mechatronics and Robotics Society of the Philippines 